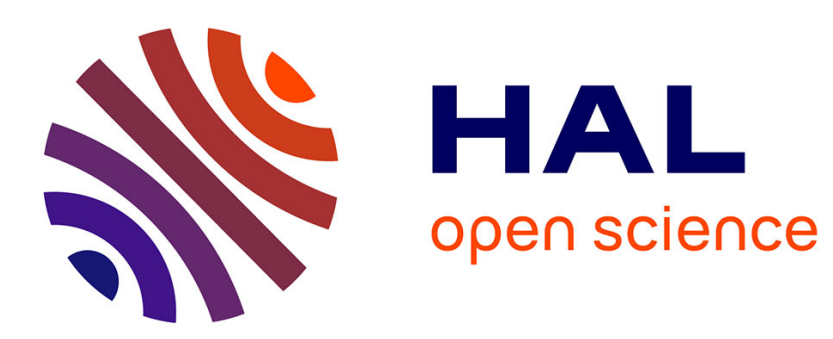

\title{
Ovarian Cancer In The Elderly: Impact Of Surgery On Morbidity And Survival
}

E. Chéreau, M. Ballester, F. Selle, Roman Rouzier, E. Daraï

\section{To cite this version:}

E. Chéreau, M. Ballester, F. Selle, Roman Rouzier, E. Daraï. Ovarian Cancer In The Elderly: Impact Of Surgery On Morbidity And Survival. EJSO - European Journal of Surgical Oncology, 2011, 37 (6), pp.537. 10.1016/j.ejso.2011.03.136 . hal-00696626

\section{HAL Id: hal-00696626 https://hal.science/hal-00696626}

Submitted on 13 May 2012

HAL is a multi-disciplinary open access archive for the deposit and dissemination of scientific research documents, whether they are published or not. The documents may come from teaching and research institutions in France or abroad, or from public or private research centers.
L'archive ouverte pluridisciplinaire HAL, est destinée au dépôt et à la diffusion de documents scientifiques de niveau recherche, publiés ou non, émanant des établissements d'enseignement et de recherche français ou étrangers, des laboratoires publics ou privés. 


\section{Accepted Manuscript}

Title: Ovarian Cancer In The Elderly: Impact Of Surgery On Morbidity And Survival

Authors: E. Chéreau, MD M. Ballester, MD F. Selle, MD R. Rouzier, MD, PhD E. Daraï, MD, PhD

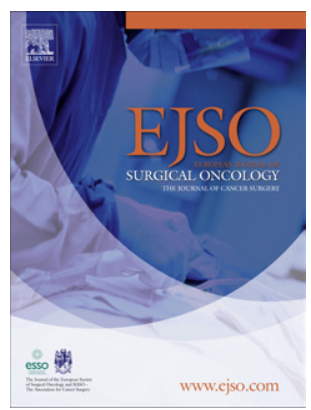

PII:

S0748-7983(11)00241-1

DOI:

10.1016/j.ejso.2011.03.136

Reference: $\quad$ YEJSO 3144

To appear in: European Journal of Surgical Oncology

Accepted Date: 28 March 2011

Please cite this article as: Chéreau E, Ballester M, Selle F, Rouzier R, Daraï E. Ovarian Cancer In The Elderly: Impact Of Surgery On Morbidity And Survival, European Journal of Surgical Oncology (2011), doi: 10.1016/j.ejso.2011.03.136

This is a PDF file of an unedited manuscript that has been accepted for publication. As a service to our customers we are providing this early version of the manuscript. The manuscript will undergo copyediting, typesetting, and review of the resulting proof before it is published in its final form. Please note that during the production process errors may be discovered which could affect the content, and all legal disclaimers that apply to the journal pertain. 
Ovarian cancer in the elderly: impact of surgery on morbidity and survival

\author{
E Chéreau $^{1} \mathrm{MD}, \mathrm{M}^{\text {Ballester }}{ }^{1} \mathrm{MD}, \mathrm{F}$ Selle ${ }^{2} \mathrm{MD}$, \\ R Rouzier ${ }^{1} \mathrm{MD}, \mathrm{PhD}, \mathrm{E}$ Daraï ${ }^{1} \mathrm{MD}, \mathrm{PhD}$
}

1. Department of Gynecology-Obstetrics,

2. Department of Medical Oncology,

Hôpital Tenon, Assistance Publique des Hôpitaux de Paris

CancerEst, Université Pierre et Marie Curie

Paris 6, France.

\title{
Correspondence:
}

Elisabeth Chéreau

Service de Gynécologie-Obstétrique

Hôpital Tenon, 4 rue de la Chine

75020 Paris, France

Tel 0033156017318

Fax 0033156017317

e-mail: elisabeth.chereau@gmail.com 
Abstract

Background: Elderly ovarian cancer patients often undergo non-optimal surgery due to their age despite of the high risk of recurrence. The aim of this study was to determine if more postoperative complications occurred in patients over 70 years and to compare extent of surgery with younger patients.

Materials and Methods: Between 2001 and 2009, 172 patients with ovarian cancer were included. We compared patient characteristics, surgical course, postoperative complications and outcome for patients under and over 70 years.

Results: 143 patients were under 70 years and 29 over. There were no difference between the two groups for tumors carateristics, time of surgery, FIGO stage, standard surgical procedures and rate of optimal resection. Patients over 70 years had less peritoneal surgery $(\mathrm{p}<0.001)$ especially diaphragmatic surgery $(\mathrm{p}=0.006)$, pelvic $(\mathrm{p}=0.02)$ and para aortic $(\mathrm{p}=0.003)$ lymphadenectomy. There was no difference in the occurence of per- or post operative complications and patients over 70 years had shorter duration of hospitalisation $(p=0.04)$. There was no difference between the two groups for disease free survival (DFS) $(\mathrm{p}=0.08)$ but overall survival (OS) was better in patients under 70 years $(\mathrm{p}=0.002)$.

Conclusion: Elderly ovarian cancer patients undergo less extensive surgery and have lower OS despite similar postoperative morbidity, optimal resection and DFS. OS decrease could be explained by difference in the management of recurrences.

Key words: ovarian cancer; elderly; optimal surgery; morbidity; outcome 


\section{Introduction}

Cumulative data support that complete cytoreduction with adjuvant or neo-adjuvant chemotherapy is the cornerstone treatment for advanced epithelial ovarian cancer ${ }^{1,2}$. However, as the peak of incidence of ovarian cancer is 61 years a high proportion of patients are elderly and this raises specific concerns about the choice of therapeutic strategy.

Therapeutic management of these patients constitutes a challenge between achieving the goal of complete cytoreduction to improve survival, and the occurrence of postoperative complications, which can lead to severe outcome or death. Recent studies have suggested that elderly patients are less likely to be optimally debulked ${ }^{3}$, receive standard therapy less often ${ }^{4-6}$ and are less able to tolerate medical treatments ${ }^{7}$. Furthermore, patients over 65 years are rarely included in clinical trials. Overall then, management of these patients remains a matter of debate ${ }^{8}$.

Aletti et al ${ }^{9}$ demonstrated that the main independent predictors of morbidity were age, American Society of Anesthesia (ASA) status, and surgical complexity score. Cloven et al reported up to $20 \%$ of mortality in patients over 80 years ${ }^{3}$. Nevertheless, geriatric practitioners believe that the physiological age should be taken into account when evaluating patients so as to be able to adopt the most effective treatment approach ${ }^{10}$. And while Chi et al ${ }^{11}$ have proposed a nomogram to evaluate survival in this group of patients, few data are available on management of ovarian cancer in elderly ${ }^{3-6,12-14}$.

Therefore, the purpose of this retrospective study was to determine whether patients over 70 years were more likely to undergo incomplete or less aggressive surgery and experience more postoperative complications and worse outcome. 


\section{Materials and methods}

From 2001 to 2009, 172 patients underwent surgery for ovarian cancer in our department of gynaecologic surgery. Individual records of all the patients were reviewed and analyzed. Patient and tumor characteristics, intraoperative findings, postoperative courses and outcomes were analyzed.

Patients were divided into two groups according to their age: under or over 70 years. Surgical procedures were separated into standard procedures and upper abdominal surgery including splenectomy, cholecystectomy, distal pancreatectomy, liver resection and lesser omentum resection. Residual disease was reported as complete (no residual disease, CC0), optimal (CC1 i.e. residual disease less than $2.5 \mathrm{~mm}$ ) or sub-optimal (CC2 i.e. residual disease between 2.5 and $25 \mathrm{~mm}$ ) according to the Sugarbaker score of cytoreduction ${ }^{15}$.

Intraoperative estimated blood loss, operative time, and length of hospitalization were recorded. Postoperative complications such as digestive fistula, lymphocyst and infection were also recorded. Disease-free survival (DFS) and overall survival (OS) were calculated and compared between the two groups. All the women gave informed written consent to therapeutic procedures and to the analysis of data related to their malignancy in accordance with institutional guidelines and the Declaration of Helsinki.

\section{Statistical Analysis}

Data were analyzed using the chi-square test, t-test and Mann Whithney test. Differences were considered significant at a level of $\mathrm{p}<0.05$. Overall survival time was calculated in months from the date of surgery to death, or the date of last follow-up for surviving patients and DFS time from the date of surgery to recurrence. The Kaplan-Meier method was used to estimate the survival distribution and comparisons of survival were made by the use of the log-rank test. 


\section{Results}

\section{Epidemiological and surgical characteristics of the population}

Patients and surgical characteristics are reported in Table 1. A hundred and forty-three patients were under 70 years (group $<70 y$ ) and 29 patients were over 70 years (group $\geq 70 y$ ). Mean age was 54.3 years in the group $<70 y$ and 75.8 years in the group $\geq 70 y$. The comorbidity rate in the group $<70 \mathrm{y}$ and the group $\geq 70 \mathrm{y}$ was $49 \%$ and $69 \%$, respectively $(\mathrm{p}=0.06)$. There were no differences in the mean preoperative CA 125 serum level, proportion of patients undergoing initial or interval surgery after neoadjuvant chemotherapy, and proportion of FIGO stage between groups. The mean number of chemotherapy cycles during neoadjuvant chemotherapy was also not different $(5$ cycles $+/-2$ for $>70 y, 6$ cycles $+/-4$ for $<70 \mathrm{y}$ ). Among the patients of $>70 \mathrm{y}$ group, 6 could not acchieved at least six cycles of chemotherapy (neoadjuvant and adjuvant chemotherapy). One patient died in the post operative course, the five others were not able to afford the whole treatment. According to our local guidelines, all patients received association of platinum and taxane during the first line of chemotherapy.

The mean operative time was shorter for the group $\geq 70 y(p=0.04)$. No difference was found between the groups in the mean estimated blood loss or in the type of resection at the end of surgery; optimal resection was obtained in $86 \%$ of patients in the group < $70 \mathrm{y}$ and $90 \%$ in the group $\geq 70 y$. In the group $\geq 70 y$ there was less peritoneal surgery $(\mathrm{p}<0.001)$, and pelvic $(\mathrm{p}=0.02)$ and para-aortic $(\mathrm{p}=0.003)$ lymphadenectomy. For upper abdominal surgery, the only statistical difference was for diaphragmatic surgery that was less often performed in the group $\geq 70 \mathrm{y}(\mathrm{p}=0.006)$.

Using Aletti's surgical complexity score (SCS) system based upon complexity and the number of surgical procedures performed ${ }^{9}$, the rate of patients with low, intermediate or high 
SCS were respectively $36 \%, 36 \%$ and $28 \%$ in the group $<70 \mathrm{y}$ and $55 \%, 41 \%$ and $4 \%$ in the group $\geq 70 \mathrm{y}$. The proportion of patients with a low SCS was higher in the group $\geq 70 \mathrm{y}$ $(\mathrm{p}=0.01)$

Seven intraoperative complications occurred in the group $<70 \mathrm{y}$ compared with only one in the group $\geq 70 \mathrm{y}$ without reaching a statistical significance (Table 2). Patients $\geq 70$ years had a shorter duration of hospitalisation both in the intensive care unit $(p=0.04)$ and overall ( $\mathrm{p}=0.03$ ). No difference in the rate of postoperative complications was observed $(28 \%$ in the group $<70 \mathrm{y}$ and $10 \%$ in the group $\geq 70 \mathrm{y}$ ) whatever in terms of digestive fistula, lymphocyst, pneumothorax, pulmonary embolism,fever, infection, pleural effusion and iterative surgery. In each group one patient died in the post operative time. In group <70y from pulmonary embolism and in group $>70 \mathrm{y}$ from septic shock.

\section{Survival}

The mean follow-up time for survival patients was $42.1+/-25$ months. The two-year DFS was $57 \%$ for the group $<70 y$ and $35 \%$ for the group $\geq 70 y$. The five-year DFS was $40 \%$ for the group $<70 \mathrm{y}$ and $23 \%$ for the group $\geq 70 \mathrm{y}$. There was no significant difference between the two groups (p (log Rank)=0.08) (Figure 1). The five-year OS was lower in the group $\geq 70 \mathrm{y}$ than in the group $<70 \mathrm{y}: 55 \%$ and $70 \%$ respectively $(\mathrm{p}(\log$ Rank $)=0.002)$ (Figure 2). All deceased patients died of their cancer. 


\section{Discussion}

The present study has demonstrated that five-year overall survival (OS) in patients with ovarian cancer is lower in patients aged 70 years or over in spite of similar complete cytoreduction and surgical complications rates to patients under 70 years. Two-year DFS is similar in the two groups. This difference cannot be explained by differences in the epidemiological characteristics of patients as no difference in comorbidity and FIGO stages were observed between the groups. Hence, in addition to the age, other parameters such as variations in surgical or adjuvant therapies could play a role. The absence of difference for surgical outcome despite a lower proportion of peritoneal and diaphragmatic surgery between the groups with same rate of advanced stage could be explained by a higher rate of patients with 3C FIGO stage related to positive paraaortic lymph nodes in the $>70 y$ group ( $4 \%$ in the $<70 \mathrm{y}$ group and $16 \%$ in the $>70 \mathrm{y}$ group $(\mathrm{p}=0.02))$.

\section{Impact of lymphadenectomy on survival}

A closer look at the type of surgery performed in both groups shows that, although there was no difference in the rate of complete and optimal cytoreduction, there were lower rates of pelvic and paraaortic lymphadenectomy and peritoneal surgery in the older group. This is of particular importance especially for patients with advanced stages of ovarian cancer, which was the case for most of our patients. When the residual disease was taken into account, Beneditti Panici et al ${ }^{16}$ showed that the hazard ratios for occurrence of the first event and mortality from any cause were almost unchanged. However, analyzing the surveillance, epidemiology, and end results (SEER) database for the period from 1988 to 2001 when taxanes were little used, Chan et al ${ }^{17}$ underlined the detrimental impact of not performing lymphadenectomy. A similar recent study using the SEER database on the period up to 2004 when taxanes were widely used as in our population, Rouzier et al ${ }^{18}$ also confirmed the 
positive impact of performing lymphadenectomy independently of the extent of cytoreduction. This advantage was proved for women with stage-II ovarian cancer in whom the risk of incomplete cytoreductive surgery is relatively low and the incidence of lymph node involvement is only about $20 \%$ as well as for patients with stage IIIC and IV. All these data reinforce the fact that surgical effort even in elderly women should take into account not only peritoneal disease but also retroperitoneal spread.

\section{Morbidity according to the extent of surgery}

The risk ratio of extensive surgery including diaphragmatic removal and lymphadenectomy in elderly women deserves discussion due to the risk of postoperative complications. Although no difference in the overall complication rate was found between the two groups in our study, three patients in the group $<70 y$ developed digestive fistula compared with none in the group $\geq 70 y$. Moreover, lymphocyst, pneumothorax or pulmonary embolism were only observed in the group of patients under 70 years. In accordance with Chi et al ${ }^{19}$, although cytoreductive surgery and chemotherapy offer the best chance of long term survival, this strategy in elderly patients is associated with a significant morbidity and mortality, hence patients and their families should be counseled on these potential risks. Using Aletti's surgical complexity score (SCS) system ${ }^{9}$, the association of pelvic and paraaortic lymphadenectomy to other surgical procedures shifts one third of the patients $\geq 70$ years from low to intermediate or high SCS groups. Aletti et al underlined that the relative risk of postoperative complication compared to low SCS were 1.35 and 4.59 for intermediate and high SCS groups respectively. A recent study has confirmed the relevance of the Aletti scoring system to predict postoperative complications with an area under the ROC curve superior to Fagotti, Fagotti modified, Sugarbaker's Peritoneal Cancer Index, Eisenkop and FIGO classification ${ }^{20}$. However, the relevance of the SCS system to evaluate OS and DFS 
was not confirmed ${ }^{9}$.

\section{Criteria to opt for extensive surgery}

In a previous study ${ }^{21}$ using a multivariable analysis, the decision to perform lymph node assessment appeared dependent on the surgeon's choice, low residual disease, an ASA of 1 or 2 and the absence of carcinomatosis. Once lymphadenectomy had been decided on, the main independent criterion to perform complete lymphadenectomy versus lymph node sampling was a patient age of under 65 years. However, as there is a lack of clear recommendations for patients over 65 years linked to them being underrepresented in clinical trials $^{8}$, these criteria would seem to be subjective. There is therefore a need for objective criteria to opt for extensive surgery including pelvic and paraaortic lymphadenctomy. Chi et al ${ }^{11}$ advocated the use of a nomogramme to predict survival taking into account age at surgery, tumor grade, histology, preoperative platelet count, presence of ascites and residual disease. Except for tumor grade, which is sometimes difficult to assess on intraoperative histology but which has little impact on the nomogram score, these parameters are evaluable during surgery and could be used to opt for lymphadenectomy in patients with a high probability of survival.

\section{Impact of chemotherapy regimen on survival}

In addition to surgical effort, neo-adjuvant or adjuvant platinum/taxane based chemotherapy is the cornerstone for treating patients with advanced stages of ovarian cancer. In our study, no difference in the rate of neo-adjuvant chemotherapy or in the chemotherapy regimen was noted between the groups. Therefore, the difference in survival between the groups cannot be explained by this parameter. Brun et al ${ }^{22}$ showed that neo-adjuvant chemotherapy leads to a high rate of complete cytoreduction in nearly three quarters of 
patients and offers similar survival to initial surgery. However, a recent meta-analysis on interval debulking surgery found no advantage on survival of this option compared to initial surgery followed by adjuvant chemotherapy ${ }^{23}$. Despite its proven efficacy in treating ovarian cancer, chemotherapy seems to be used less in elderly patients. In a multiple logistic regression model with patients aged 65 to 69 years as the reference, Sundararajan et al ${ }^{4}$ found that the odds ratios of receiving chemotherapy were 0.96 for ages 70 to $74,0.65$ for 75 to 79 , 0.24 for 80 to 84 , and 0.12 for patients over 85 years. Moreover, among patients over 80 years who underwent complete cytoreductive surgery, $13 \%$ were unable to receive adjuvant therapy.

This contrasts with the data of Eisenhauer et al ${ }^{24}$ showing that patients over 65 years had similar rates of initial response, platinum resistance, DFS and OS to younger patients. This also contrasts with the potential benefit of chemotherapy, especially neo-adjuvant. Indeed, McLean et al ${ }^{14}$ demonstrated that neo-adjuvant chemotherapy was associated with odds ratios of 0.80 (95\% CI 0.37-1.75) for surgical complications and 0.79 (95\% CI 0.331.90) for chemotherapeutic complications in elderly women. Further studies are required to evaluate whether neo-adjuvant chemotherapy should be the first line therapy in elderly women.

\section{Limitations of study on elderly patients}

Some limitations of the present study have to be underlined. First, the retrospective nature cannot exclude the risk of potential bias such as the exclusion of patients from first surgical effort linked to age. Second, there is a lack of consensus about what constitutes an elderly patient. Gardner reported that the term "elderly" has been variably defined in the ovarian cancer debulking literature as being older than 60,70, or 80+ years of age. However, most studies determine a cut-off for elderly women as patients aged 70 years or more ${ }^{4-7}$ 
which is what we opted to use here. Third, no attempt was made to replace the birth age by criteria evaluating life expectancy. Further studies are required to evaluate the contribution of geriatric evaluation to define patients with high life expectancy that could benefit from initial surgical effort including lymphadenectomy. Finaly, the decrease in OS for elderly patients observed in our study could be explained by difference in the management at the time of recurrence. Indeed, patients over 70 years are usually not included in medical trials and so couldn't benefit from new therapy.

\section{Conclusion}

Our results support that as many elderly patients with ovarian cancer benefit from complete cytoreductive surgery as younger patients. However, extensive surgery including lymphadenectomy was less frequently performed in patients $\geq 70$ years impacting on overall survival. There is therefore a need to establish objective criteria to identify elderly candidates who could benefit from lymphadenectomy and extensive peritoneal resection such as diaphragmatic surgery.

\section{Conflict of interest statement}

None of the authors had any financial and personal relationships with other people or organisations that could inappropriately influence this work. 


\section{References}

1. BRISTOW RE, TOMACRUZ RS, ARMSTRONG DK, TRIMBLE EL, MONTZ FJ. Survival effect of maximal cytoreductive surgery for advanced ovarian carcinoma during the platinum era: a meta-analysis. J Clin Oncol 2002;20:1248-59.

2. CHI DS, EISENHAUER EL, LANG J, et al. What is the optimal goal of primary cytoreductive surgery for bulky stage IIIC epithelial ovarian carcinoma (EOC)? Gynecol Oncol 2006;103:559-64.

3. CLOVEN NG, MANETTA A, BERMAN ML, KOHLER MF, DISAIA PJ. Management of ovarian cancer in patients older than 80 years of Age.. Gynecol Oncol 1999;73:137-9.

4. SUNDARARAJAN V, HERSHMAN D, GRANN VR, JACOBSON JS, NEUGUT AI. Variations in the use of chemotherapy for elderly patients with advanced ovarian cancer: a population-based study.J Clin Oncol 2002;20:173-8.

5. UYAR D, FRASURE HE, MARKMAN M, VON GRUENIGEN VE. Treatment patterns by decade of life in elderly women ( $>$ or $=70$ years of age) with ovarian cancer. Gynecol Oncol 2005;98:403-8.

6. MARKMAN M, LEWIS JLJ, SAIGO P, et al. Epithelial ovarian cancer in the elderly. The Memorial Sloan-Kettering Cancer Center experience. Cancer 1993;71:634-7.

7. MOORE KN, REID MS, FONG DN, et al. Ovarian cancer in the octogenarian: does the paradigm of aggressive cytoreductive surgery and chemotherapy still apply? Gynecol Oncol 2008;110:133-9.

8. LEWIS JH, KILGORE ML, GOLDMAN DP, et al. Participation of patients 65 years of age or older in cancer clinical trials. J Clin Oncol 2003;21:1383-9.

9. ALETTI GD, DOWDY SC, PODRATZ KC, CLIBY WA. Relationship among surgical complexity, short-term morbidity, and overall survival in primary surgery for advanced ovarian cancer. Am J Obstet Gynecol 2007;197:676 e1-7. 
10. STEER CB. Chemotherapy for ovarian cancer in the older adult. Curr Treat Options Oncol 2009;10:159-70.

11. CHI DS, PALAYEKAR MJ, SONODA Y, et al. Nomogram for survival after primary surgery for bulky stage IIIC ovarian carcinoma. Gynecol Oncol 2008;108:191-4.

12. MARCHETTI DL, LELE SB, PRIORE RL, MCPHEE ME, HRESHCHYSHYN MM. Treatment of advanced ovarian carcinoma in the elderly. Gynecol Oncol 1993;49:86-91.

13. DIAZ-MONTES TP, ZAHURAK ML, GIUNTOLI RLN, et al. Surgical care of elderly women with ovarian cancer: a population-based perspective. Gynecol Oncol 2005;99:352-7.

14. MCLEAN KA, SHAH CA, THOMPSON SA, GRAY HJ, SWENSEN RE, GOFF BA. Ovarian cancer in the elderly: outcomes with neoadjuvant chemotherapy or primary cytoreduction. Gynecol Oncol 2010;118:43-6.

15. SUGARBAKER PH. Management of peritoneal-surface malignancy: the surgeon's role. Langenbecks Arch Surg 1999;384:576-87.

16. BENEDETTI PANICI P, PERNIOLA G, ANGIOLI R, et al. Bulky lymph node resection in patients with recurrent epithelial ovarian cancer: impact of surgery. Int J Gynecol Cancer 2007; 17:1245-51.

17. CHAN JK, URBAN R, HU JM, et al. The potential therapeutic role of lymph node resection in epithelial ovarian cancer: a study of 13918 patients. Br J Cancer 2007;96:181722.

18. ROUZIER R, BERGZOLL C, BRUN JL, et al. The role of lymph node resection in ovarian cancer: analysis of the surveillance, epidemiology, and end results (SEER) database. BJOG 2010.

19. CHI DS, FRANKLIN CC, LEVINE DA, et al. Improved optimal cytoreduction rates for stages IIIC and IV epithelial ovarian, fallopian tube, and primary peritoneal cancer: a change in surgical approach. Gynecol Oncol 2004;94:650-4. 
20. CHEREAU E, BALlESTER M, SElle F, CORTEZ A, DARAI E, ROUZIER R. Comparison of peritoneal carcinomatosis scoring methods in predicting resectability and prognosis in advanced ovarian cancer. Am J Obstet Gynecol 2010;202:178 e1-78 e10.

21. ALETTI GD, GOSTOUT BS, PODRATZ KC, CLIBY WA. Ovarian cancer surgical resectability: relative impact of disease, patient status, and surgeon. Gynecol Oncol 2006;100:33-7.

22. BRUN JL, ROUZIER R, SELLE F, HOURY S, UZAN S, DARAI E. Neoadjuvant chemotherapy or primary surgery for stage III/IV ovarian cancer: contribution of diagnostic laparoscopy. BMC Cancer 2009;9:171.

23. TANGJITGAMOL S, MANUSIRIVITHAYA S, LAOPAIBOON M, LUMBIGANON P. Interval debulking surgery for advanced epithelial ovarian cancer. Cochrane Database Syst Rev 2009:CD006014.

24. EISENHAUER EL, TEW WP, LEVINE DA, et al. Response and outcomes in elderly patients with stages IIIC-IV ovarian cancer receiving platinum-taxane chemotherapy. Gynecol Oncol 2007;106:381-7. 


\section{Figures Legends}

Figure 1: Disease free survival

Figure 2: Overall survival 
Table 1: Patients and surgical characteristics

\begin{tabular}{|c|c|c|c|}
\hline & $\begin{array}{l}\text { Group } 1 \\
<70 \text { years } \\
\quad \text { n }(\%)\end{array}$ & $\begin{aligned} & \text { Group } 2 \\
\geq & 70 \text { years } \\
& \text { n }(\%)\end{aligned}$ & $\mathbf{p}$ \\
\hline Number of patients & 143 & 29 & \\
\hline Median age (range) & $54.3(22-68)$ & $75.8(70-91)$ & $<0.001$ \\
\hline Co morbidity & $71(49 \%)$ & $20(69 \%)$ & 0.06 \\
\hline $\begin{array}{l}\text { Time of surgery } \\
\text { - initial } \\
\text { - interval }\end{array}$ & $\begin{array}{l}108(75 \%) \\
35(25 \%)\end{array}$ & $\begin{array}{c}23(79 \%) \\
6(21 \%)\end{array}$ & 0.84 \\
\hline CA 125 at diagnosis (UI/ml) (range) & $1728(6-31210)$ & $898(14-8190)$ & 0.32 \\
\hline 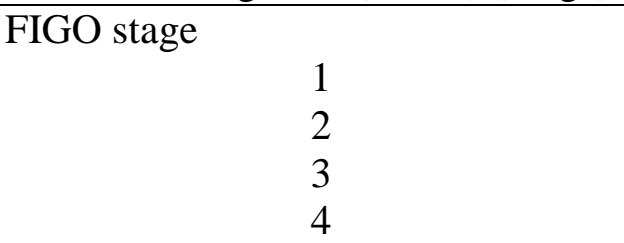 & $\begin{array}{l}26(18 \%) \\
17(12 \%) \\
89(62 \%) \\
11(8 \%)\end{array}$ & $\begin{array}{c}4(14 \%) \\
1(3 \%) \\
24(83 \%) \\
0\end{array}$ & 0.12 \\
\hline $\begin{array}{l}\text { Standard Surgery } \\
\text { Unilateral or bilateral salpingo- } \\
\text { oophorectomy } \\
\text { Hysterectomy } \\
\text { Omentectomy } \\
\text { Appendectomy } \\
\text { Peritoneal surgery } \\
\text { Intestinal resection } \\
\text { Pelvic lymphadenectomy } \\
\text { Para aortic lymphadenectomy }\end{array}$ & $\begin{array}{l}135(94 \%) \\
117(82 \%) \\
130(91 \%) \\
61(43 \%) \\
42(29 \%) \\
53(37 \%) \\
89(62 \%) \\
85(59 \%)\end{array}$ & $\begin{array}{c}28(97 \%) \\
24(83 \%) \\
23(79 \%) \\
9(31 \%) \\
2(7 \%) \\
7(24 \%) \\
11(38 \%) \\
8(28 \%)\end{array}$ & $\begin{array}{c}0.9 \\
0.88 \\
0.13 \\
0.33 \\
<\mathbf{0 . 0 0 1} \\
0.26 \\
\mathbf{0 . 0 2} \\
\mathbf{0 . 0 0 3}\end{array}$ \\
\hline $\begin{array}{l}\text { Upper abdominal surgery } \\
\text { Cholecystectomy } \\
\text { Splenectomy } \\
\text { Liver resection } \\
\text { Partial gastrectomy } \\
\text { Distal pancreatectomy }\end{array}$ & $\begin{array}{l}26(18 \%) \\
6(4 \%) \\
8(6 \%) \\
6(4 \%) \\
4(3 \%) \\
3(2 \%)\end{array}$ & $\begin{array}{l}2(7 \%) \\
1(3 \%) \\
1(3 \%) \\
0 \\
0 \\
0\end{array}$ & $\begin{array}{l}0.22 \\
0.7 \\
0.98 \\
0.57 \\
0.81 \\
0.99\end{array}$ \\
\hline Diaphragmatic surgery & $35(25 \%)$ & 0 & 0.006 \\
\hline $\begin{array}{l}\text { Mean operative time (min) (range) } \\
\text { Estimated blood loss (ml) (range) }\end{array}$ & $\begin{array}{c}412(150-660) \\
892(100-5000)\end{array}$ & $\begin{array}{c}321(180-420) \\
1125(300-3500)\end{array}$ & $\begin{array}{c}\mathbf{0 . 0 4} \\
0.8\end{array}$ \\
\hline $\begin{array}{l}\text { Resection } \\
\text { Complete CC0 } \\
\text { Optimal CC1 } \\
\text { Sub-optimal CC2 }\end{array}$ & $\begin{array}{l}99(71 \%) \\
21(15 \%) \\
20(14 \%)\end{array}$ & $\begin{array}{l}21(73 \%) \\
5(17 \%) \\
3(10 \%)\end{array}$ & 0.83 \\
\hline
\end{tabular}


Table 2: Surgical outcome

\begin{tabular}{|c|c|c|c|}
\hline & $\begin{array}{l}\text { Group } 1 \\
<70 \text { years } \\
\text { n }(\%)\end{array}$ & $\begin{array}{c}\text { Group } 2 \\
\geq 70 \text { years } \\
\quad \text { n }(\%) \\
\end{array}$ & $\mathbf{p}$ \\
\hline $\begin{array}{l}\text { Length of hospitalization } \\
\text { (days) (range) }\end{array}$ & $12.9(2-38)$ & $9.3(5-16)$ & 0.03 \\
\hline $\begin{array}{l}\text { Length of hospitalization in } \\
\text { intensive care unit (days) } \\
\text { (range) }\end{array}$ & $2.1(0-15)$ & $0.86(0-2)$ & 0.04 \\
\hline Per-operative complication & $7(5 \%)$ & $1(3 \%)$ & 0.88 \\
\hline Post-operative complication & $40(28 \%)$ & $3(10 \%)$ & 0.08 \\
\hline - Digestive fistula & $3(2 \%)$ & 0 & 0.99 \\
\hline - Lymphocyst & $10(7 \%)$ & 0 & 0.3 \\
\hline - Fever & $19(13 \%)$ & $(3 \%)$ & 0.23 \\
\hline - infection & $12(8 \%)$ & $2(7 \%)$ & 0.9 \\
\hline - Pleural effusion & $12(8 \%)$ & $1(3 \%)$ & 0.6 \\
\hline - Pneumothorax & $2(1 \%)$ & 0 & 0.75 \\
\hline - Pulmonary embolism & $3(2 \%)$ & 0 & 0.99 \\
\hline Iterative surgery & $15(10 \%)$ & $1(3 \%)$ & 0.4 \\
\hline
\end{tabular}


Figure 1: Disease free survival

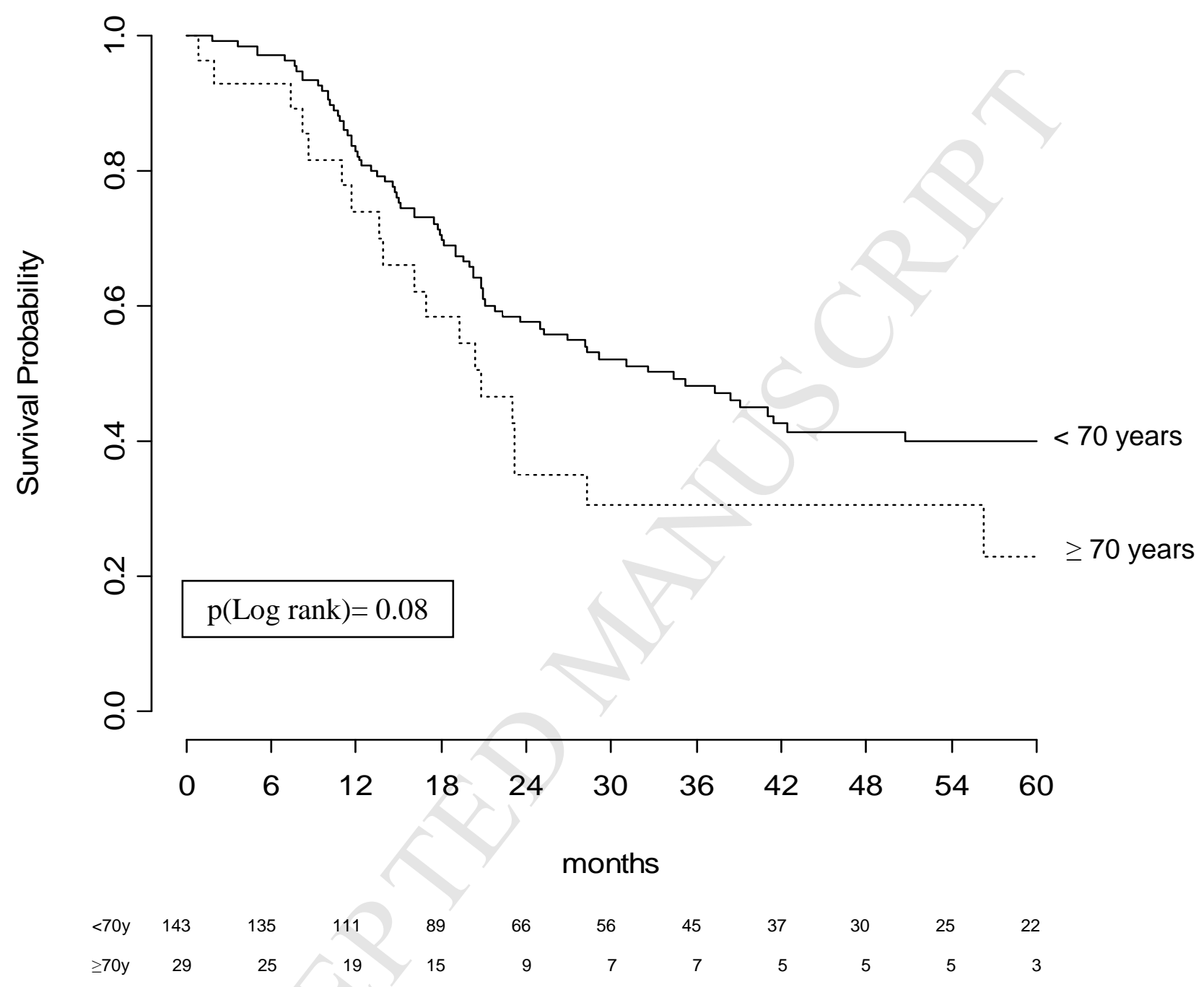


Figure 2: Overall Survival

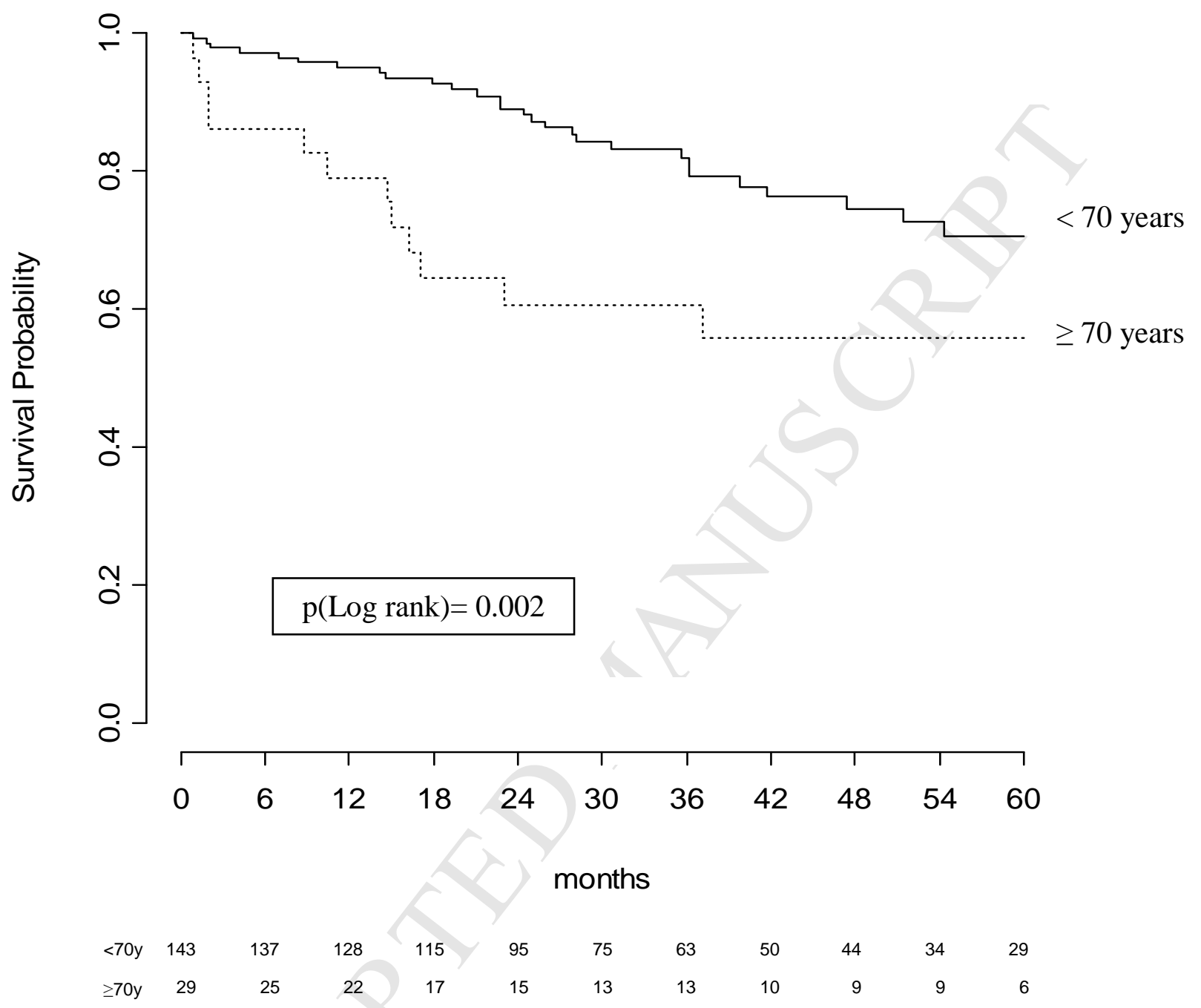

